|Agr. Biol. Chem., Vol. 29, No. 11, p. 1021 1026, 1965]

\title{
Phenylalanine Ammonia-Lyase in Sliced Sweet Potato Roots
}

\author{
Effect of Antibiotics on the Enzyme Formation and its \\ Relation to the Polyphenol Biosynthesis* \\ By Takao Minamikawa and Ikuzo Uritani \\ Laboratory of Biochemistry, Faculty of Agriculture, Nagoya University, Anjo, Aichi \\ Received June 16, 1965
}

\begin{abstract}
A marked rise in the phenylalanine ammonia-lyase activity and the polyphenol synthesis was observed in sliced roots of a sweet potato. The enzyme activity was found to be localized in the root tissue adjacent to the sliced surface. In this region, the synthesis of polyphenols was much higher compared to the inner tissues. When the specific inhibitors for the protein and nucleic acid biosynthesis such as an actinomycin D and blasticidin $\mathrm{S}$ were added to the tissues by vacuum infiltration technique, both the development of phenylalanine ammonia-lyase activity and the synthesis of polyphenols were severely prevented. These results suggest the important role of phenylalanine ammonia-lyase in the polyphenol synthesis and de novo synthesis of the enzyme protein molecule in the sliced tissues.
\end{abstract}

\section{INTRODUCTION}

Koukol and Conn ${ }^{11}$ have first demonstrated the presence of phenylalanine ammonia-lyase in plant tissues. Their studies have made a basis for suggesting the participation of this enzyme in the incorporation of trans-cinnamic acid into a number of aromatic compounds in plant tissues, and has supported the Neish's original view ${ }^{2}$ concerning the role of phenylalanine in the biosynthesis of aromatic compounds. Levy and Zucker ${ }^{3 \prime}$ have reported also some experimental evidences showing the conversion of $\mathrm{L}$-phenylalanine to trans-cinnamic acid in sliced potato tubers. Neish ${ }^{4}$ has demonstrated the similar type of enzymatic deamination such as conversion of L-tyrosine to $p$-coumaric acid in some plant tissues. As the activity of tyrosine ammonia-lyase was

* This paper constitutes Part 50 of the phytopathological chemistry of sweet potato with black rot.

1) J. Koukol and E. E. Conn, J. Biol. Chem., 236, 2692 (1961).

2) A.C. Neish, Ann. Rev. Plant Physiol., 11, 55 (1960).

3) C.C. Levy and M. Zucker, J. Biol. Chem., 235, 2418 (1960).

4) A.C. Neish, Phytochem., 1, 1 (1961). very high in monocotyledons as compared to that in dicotyledons, the enzyme is assumed to take part in biosynthesis of aromatic compounds in the former type. In our previous studies, ${ }^{5.61}$ a marked increase in phenylalanine ammonia-lyase and tyrosine ammonia-lyase activities was found to occur in sweet potato roots in response to wounding or infection by Ceratocystis fimbriata. The trend of remarkable rise in phenylalanine ammonia-lyase activity in the wounded or infected root tissues showed a close relation with that of biosynthesis of polyphenols in the tissues. On the other hand, in the fresh root tissues, the concentration of polyphenols was very low and phenylalanine ammonia-lyase activity was also hardly detectable. The picture of tyrosine ammonia-lyase in the wounded or infected tissues was quite similar to the case of phenylalanine ammonialyase, but the enzyme activity was found to be very low.

\footnotetext{
5) T. Minamikawa and I. Uritani, Arch. Biochem. Biophys., 108, $573(1964)$.

6) T. Minamikawa and I. Uritani. J. Biochem., 57, 678
} 
The major polyphenols synthesized in the sweet potato roots are chlorogenic and isochlorogenic acids, ${ }^{7,8)}$ and from the biochemical informations described above, it can be surmised that these compounds may be synthesized from trans-cinnamic acid which is derived by the deamination of phenylalanine. However, a partial participation of tyrosine ammonia-lyase in the polyphenol synthesis cannot be excluded. Consequently, it has come into our question that a marked increase of the phenylalanine ammonia-lyase activity in sweet potato roots in response to wounding is due to the synthesis of the new enzyme protein or merely due to the activation of an enzyme precursor residing in the fresh root tissues. As a guide to solve this problem, an experiment was undertaken using the inhibitors of protein and nucleic acid biosynthesis and other specific antibiotics. The experimental results furnish another evidence as to close relationship between the polyphenol synthesis and the role of phenylalanine ammonia-lyase in sliced sweet potato roots.

\section{EXPERIMENTAL}

\section{Sample Preparation and Infiltration Technique}

For the experiment using inhibitors, discs $(1.5 \times$ $19 \mathrm{~mm}$, about $0.5 \mathrm{~g}$ ) of sweet potato, variety Norin No. 1, were immersed into the solution of an appropriate inhibitor and the whole material was subjected to the vacuum infiltration $(6 \mathrm{mmHg})$ for three-minute period. Usually $50 \mathrm{ml}$ of the solution was required for the infiltration of 50 discs. In parallel, discs were treated with water in the same way and were served as a reagent control. Then the discs were placed on a filter paper and incubated at $28 \sim 29^{\circ} \mathrm{C}$ in a sterilized box. After a certain period of incubation at the same temperature, discs were harvested for the polyphenol estimation and the assay of phenylalanine ammonia-lyase activity. Separately, the inhibitor was infiltrated into the root discs after the six-hour incubation period at $28 \sim 29^{\circ} \mathrm{C}$. The discs were then incubated again for a certain period. All the succeeding manupulations were in

7) I. Uritani and K. Muramatsu, J. Agr. Chem. Soc. Japan, 26, 289 (1952)

8) T. Akazawa and K. Wada, Plant Physiol., 36, 139 (1961). the same manner as before.

\section{Enzyme Assay}

The activity of phenylalanine ammonia-lyase was measured using crude enzyme preparation in the following ways. Ten discs of the incubated root samples were homogenized at $0 \sim 4^{\circ} \mathrm{C}$ with $10 \mathrm{ml}$ of $0.05 \mathrm{M}$ sodium borate buffer $(\mathrm{pH} 8.5)$ containing $0.5 \%$ sodium isoascorbate. Homogenates were squeezed through a cheese cloth and centrifuged at $14,000 \times \mathrm{g}$ for twenty minutes. The supernatant solution was passed through a column $(1.9 \times 10 \mathrm{~cm})$ of Sephadex (G-25) which was preequilibrated with $0.05 \mathrm{M}$ borate buffer ( $\mathrm{pH} 8.5$ ) and was eluted with the same buffer. Twenty $\mathrm{ml}$ effluent was collected, and an aliquot was used for the measurement of the phenylalanine ammonia-lyase activity after the method of Koukol and Conn. ${ }^{1)}$ Reaction mixture contained $20 \mu$ moles of L-phenylalanine, 80 to 100 $\mu$ moles of sodium borate buffer $(\mathrm{pH} 8.8)$ and an enzyme preparation in a total volume of $2.0 \mathrm{ml}$. The reaction was continued for one hour at $40^{\circ} \mathrm{C}$, and was stopped by adding $0.1 \mathrm{ml}$ of $6 \mathrm{~N}$ hydrochloric acid. trans-Cinnamic acid in ether-extractable fraction of the acidified reaction mixture was measured at $268 \mathrm{~m} \mu$ by spectrophotometry. The molar extinction coefficient of trans-cinnamic acid in $0.05 \mathrm{M}$ sodium hydroxide is 20,900 . One unit of the activity was defined as the amount of enzyme catalyzing the formation of $10 \mathrm{~m} \mu$ moles of trans-cinnamic acid per hour under the assay condition described above.6)

\section{Quantitative Analysis of Polyphenols}

Five discs were homogenized in hot aqueous ethanol $(80 \%)$ in a Potter-Elvehjem glass homogenizer. A resulting ethanol extract was subjected to the analysis of polyphenols by the method of Zucker and Ahrens.9) Quantities of polyphenols were expressed on the basis of $\mu$ moles of chlorogenic acid. Chlorogenic acid has been proved to be the major polyphenolic compound present in sweet potato roots.

\section{Reagents}

Sources of the reagents are as follows. Actinomycin D: Merck Sharp and Dohme Research Lab., Rahway; Antimycin A (m.p. $142^{\circ} \mathrm{C}$ ): California Corporation for Biochemical Research, Los Angeles. Puromycin dihydrochloride: Nutritional Biochemicals Corporation, Cleveland; and Blasticidin S (97\% purity): Kakenkagaku Corporation, Tokyo.

9) M. Zucker and J.F. Ahrens, Plant Physiol., 33, 246 (1958). 


\section{RESULTS AND DISCUSSION}

Distributions of Phenylalanine Ammonia-Lyase and Polyphenols in Sliced Tissues

Results of Fig. 1 representing the localization of the phenylalanine ammonia-lyase and polyphenols in the root tissues clearly show that the enzyme activity was highest in the outermost thin layer, gradually decreasing towards the inner part of the tissues. The distribution pattern of the polyphenol synthesis was found to be in well concordance with that of the enzyme activity. Apparently, it can be concluded that there is no translocation of the polyphenols from the inner part to the surface region of the tissues. These results may indicate the key role of phenylalanine ammonialyase in the biosynthesis of polyphenols in sweet potato tissues.

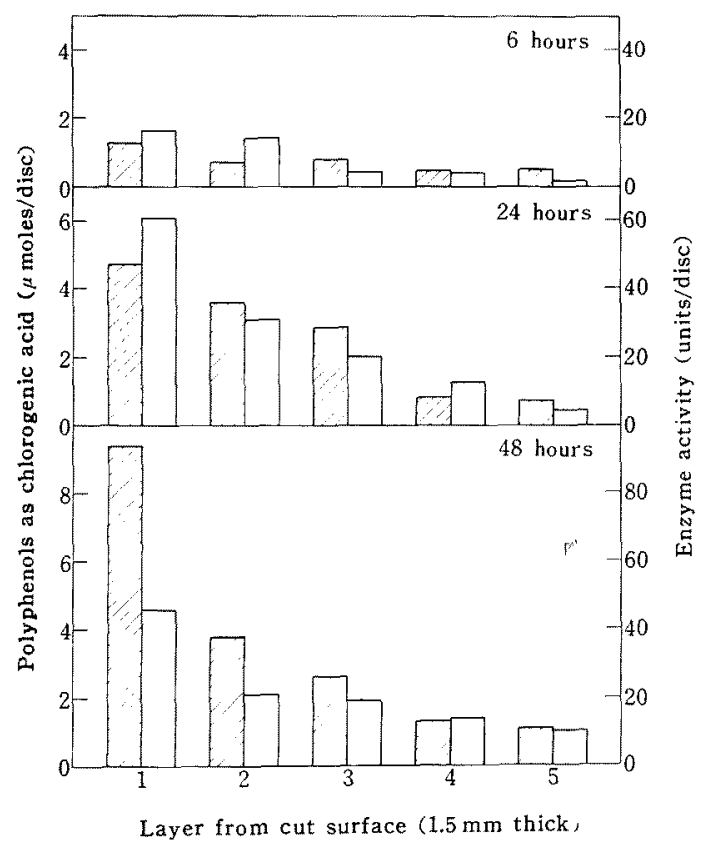

FIG. 1. Distributions of Phenylalanine AmmoniaLyase Activity and Polyphenols in Sliced Tissues.

One sweet potato root was cut to slices ( $2 \mathrm{~cm}$ thick) and they were incubated at $28 \sim 29^{\circ} \mathrm{C}$ in a moist box for the ir.dividual periods. Numbers of the abscissa correspond to the layers ( $1.5 \mathrm{~mm}$ thick) starting from the cut surface to the innermost layer.

innermost layer. Concentration of polyphenols

: Concentration of polyphenols activity.
Effect of Inhibitors on the Development of Phenylalanine Ammonia-Lyase and the Polyphenol Biosynthesis

Blasticidin $\mathrm{S}$ is known to be a potent inhibitor of the protein biosynthesis and often used for studying the mechanism of protein biosynthesis. ${ }^{10,11}$ Fig. 2 shows a time course study of the effect of blasticidin $S$ on the development of phenylalanine ammonia-lyase and on the polyphenol synthesis. In the control experiment, in which the antibiotic was replaced by water, the activity of phenylalanine ammonia-lyase showed a rapid increase until it reached a plateau at the twenty-fourthhour. Also the continueous increase of the polyphenols was obsreved in a close connection with the enzyme activity. On the other hand, in the tissues into which blasticidin $S$ was infiltrated at concentrations of 0.02 and $0.1 \mu \mathrm{g}$ per $\mathrm{ml}$, both enzyme activity and polyphenol concentration were markedly low (Fig. 2-A). Even in the system in which blasticidin $\mathrm{S}$ was added to the discs after the six-hours preincubation, the antibiotic showed a striking effect on the increase in enzyme activity and polyphenol synthesis (Fig. 2-B). An essentially similar effect was observed by the addition of actinomycin D (20 and $100 \mu \mathrm{g}$ per $\mathrm{ml}$ ) (Fig. 3). It has been known that this antibiotic prevents nucleic acid biosynthesis. ${ }^{21}$ Results in Table I represent an analogous experimental series to examine the effect of other inhibitors. In this experiment, the inhibitors were infiltrated immediately after the slicing, and the enzyme activity and polyphenols were assayed at the period of six and twenty-four hours after the incubation. Puromycin, a specific inhibitor for protein biosynthesis, ${ }^{13,14)}$ exhibited a strong inhibition on both increases in enzyme activity and polyphenol synthesis. DL- $p$ Fluorophenylalanine, an amino acid analogue,

10) S. Ou, M. Katagiri and A. Misato, Ann. Phytopathol. Soc., Japan, 27, 250 (1962).

17) S. Ou and A. Misato, ibid., 28, 93 (1963).

12) R. F. Click and D. P. Hackett, Proc. Natl. Acad. Sci., 50, 243 (1963).

13) M.B. Yarmolinsky and G.L. de La Haba, ibid,, 50, 243 (1963).

14) D. Nathans and F. Lipmann, ibid., 47, 497 (1961). 


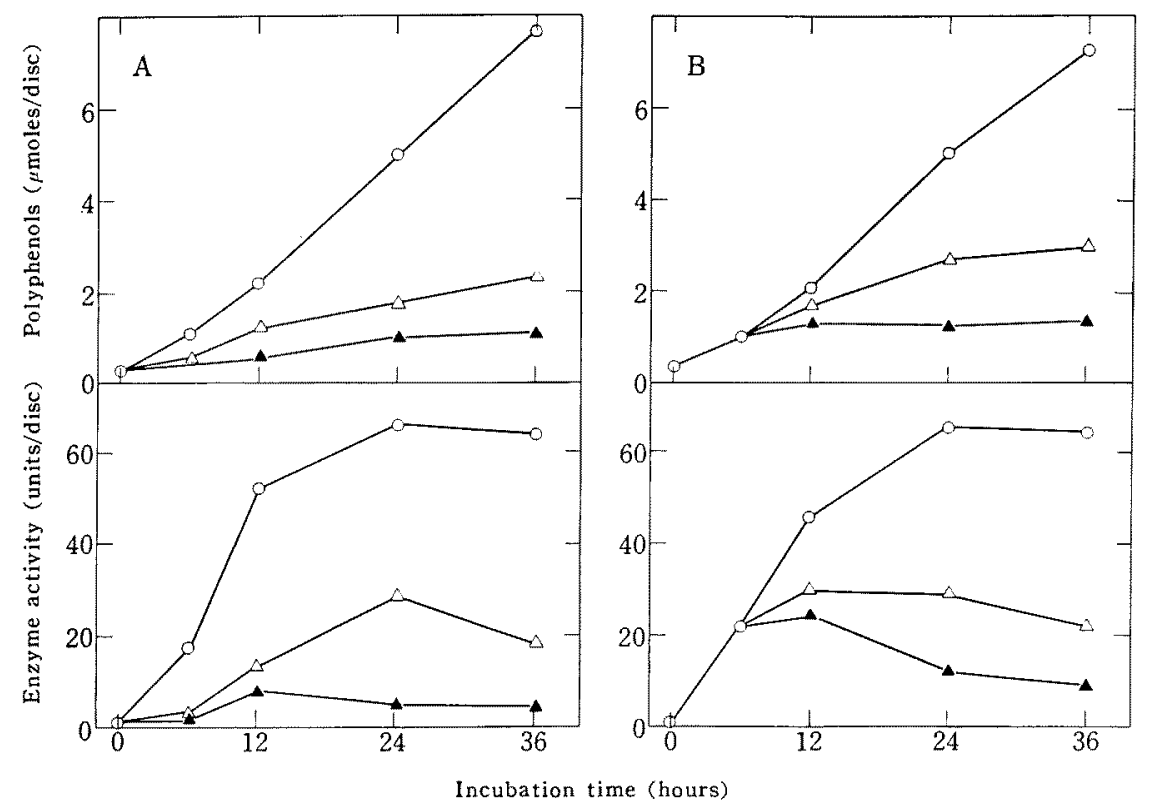

FIG. 2. Effect of Blasticidin $\mathrm{S}$ on the Development of Phenylalanine Ammonia-lyase Activity and Polyphenol Synthesis.

Blasticidin $S$ was added to discs (1.5 $\mathrm{mm}$ thick) immediately after slicing (A) and after six-hours' incubation (B).

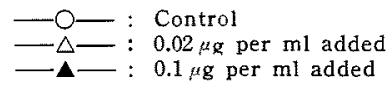

which is often used as the inhibitor of protein synthesis, also showed marked inhibitory action at the concentration range of $5 \times 10^{-4}$ to $10^{-5} \mathrm{M}$. This compound has been shown to be a competitive inhibitor for the deamination reaction of L-phenylalanine catalyzed by phenylalanine ammonia-lyase, and the $K_{i}$ value was calculated to be $10^{-4} \mathrm{M}^{15}$ ) Hence, in the present experiment, the final enzyme preparation prepared from the discs was passed through a Sephadex (G-25) column to remove $\mathrm{DL}-p$-fluorophenylalanine which was originally given to the root tissues.

If the observed rise in phenylalanine ammonia-lyase activity is indeed based on the newly synthesized enzyme protein, it is

15) T. Minamikawa and I. Uritani, J. Biochem., 58, 53 (1965). presumed that the energy produced in the respiratory system is the necessary source for the synthesis. Antimycin A and 2,4-dinitrophenol were found to prevent the increase in the enzyme activity and also the polyphenol synthesis (Table I).

The results presented in this paper may indicate that the development of phenylalanine ammonia-lyase activity in the wounded root tissues is based on the protein synthesis, and not attributable to the activation of a latent enzyme which presents in the fresh tissues.

As described in the previous paper ${ }^{6}$, a significant increase in the polyphenol synthesis occurred in sweet potato tissues in response to wounding or infection by $C$. fimbriata, while the concentration of polyphenols in the fresh tissues was extensively low. In the same 


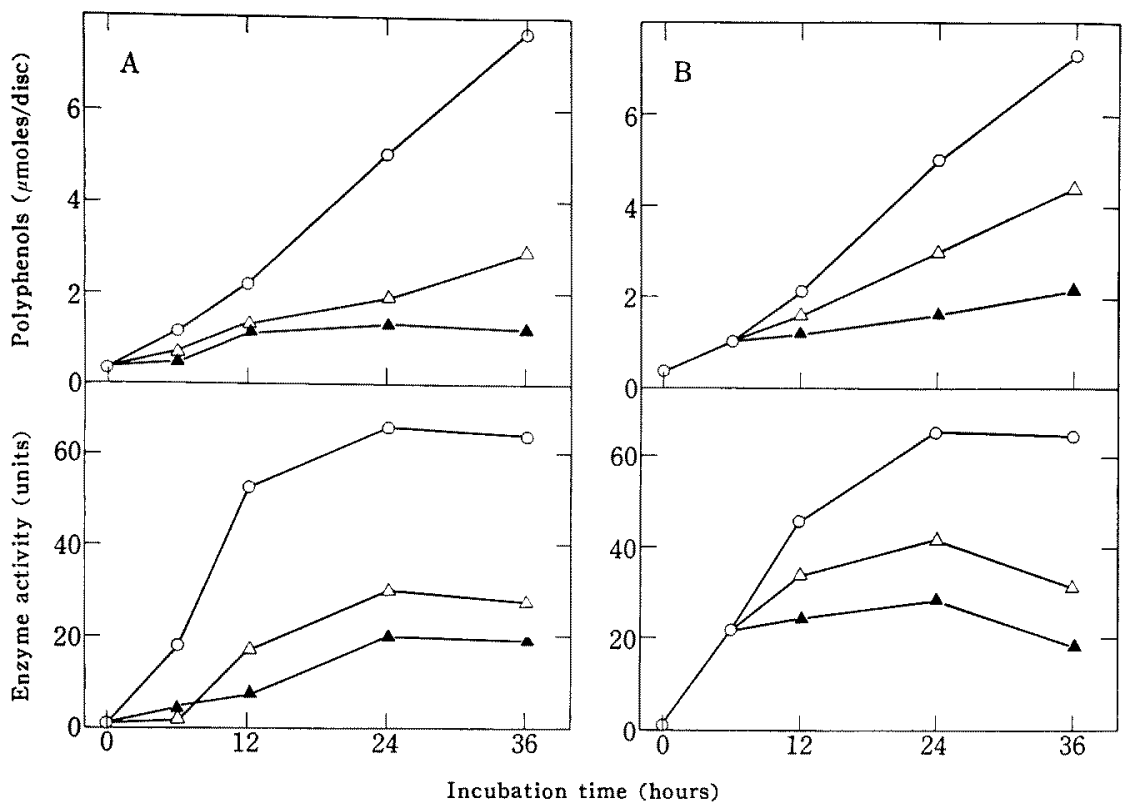

FIG. 3. Effect of Actinomycin D on the Development of Phenylalanine Ammonia-lyase Activity and Polyphenol Synthesis.

Actinomycin $D$ was added to discs ( $1.5 \mathrm{~mm}$ thick) immediately after slicing (A) and after six-hour incubation (B).

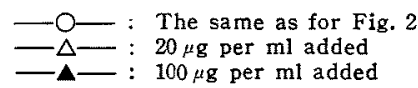

tissues, a marked rise in the activity of phenylalanine ammonia-lyase started even at the sixth-hour of incubation after slicing or fungal inoculation. The enzyme activity reached a maximum level at $24 \sim 36$ hours after incubation, and afterwards declined gradually. Hence, it is conceivable that the increased activity of phenylalanine ammonia-lyase in the injured root tissues reflects the role of this enzyme for providing phenylpropane skeletons necessary for the biosynthesis of phenolic compounds such as chlorogenic acid and isochlorogenic acid. Moreover, the experiments presented in this paper may provide further evidence as to the essential role of the phenylalanine ammonia-lyase in the biosynthetic pathway of phenolic compounds in sliced sweet potato roots. Recently, Yoshida and Shimokoriyama ${ }^{16)}$ reported the close relation between the phenylalanine ammonialyase activity and the formation of lignins in the tissues of buckwheat plant.

Finally, it should be born in mind that although phenylalanine ammonia-lyase is thought to take part in the initial step of the phenolic compound biosynthesis, the whole mechanism underlying the marked synthesis of phenolic compounds cannot be solved only by the development of the enzyme activity. Naturally, examination of other enzyme and/ or enzyme systems involved in the biosynthetic pathway of phenolic compounds is necessary, and studies along this line are being in progress in our laboratory.

16) S. Yoshida and M. Shimokoriyama, Bot. Mag. (Tokyo), 78, 14 (1965). 


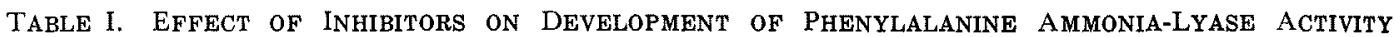
AND POLYPHENOL SYNTHESIS*

6-Hr, incubation

\begin{tabular}{|c|c|c|c|c|c|c|c|c|}
\hline \multirow{3}{*}{$\begin{array}{l}\text { Compound } \\
\text { added }(\mathbf{M})\end{array}$} & \multirow{2}{*}{\multicolumn{2}{|c|}{ Enzyme activity** }} & \multirow{2}{*}{\multicolumn{2}{|c|}{ Polyphenols*** }} & \multirow{2}{*}{\multicolumn{2}{|c|}{ Enzyme activity** }} & \multirow{2}{*}{\multicolumn{2}{|c|}{ Polyphenols** }} \\
\hline & & & & & & & & \\
\hline & $\begin{array}{l}\text { Units } \\
\text { developed } \\
\text { in 6-hr. } \\
\text { period per } \\
\text { disc }\end{array}$ & $\begin{array}{l}\text { Inhi- } \\
\text { bition } \\
(\%)\end{array}$ & $\begin{array}{l}\mu \text { moles } \\
\text { increased } \\
\text { in } 6-\mathrm{hr} . \\
\text { period per } \\
\text { disc }\end{array}$ & $\begin{array}{c}\text { Inhi- } \\
\text { bition } \\
(\%)\end{array}$ & $\begin{array}{l}\text { Units } \\
\text { developed } \\
\text { in } 24-h r . \\
\text { period per } \\
\text { ditc }\end{array}$ & $\begin{array}{c}\text { Inhi- } \\
\text { bition } \\
(\%)\end{array}$ & $\begin{array}{l}\text { umoles } \\
\text { increased } \\
\text { in } 24-h r . \\
\text { period per } \\
\text { disc. }\end{array}$ & $\begin{array}{l}\text { Inhi- } \\
\text { bition } \\
(\%)\end{array}$ \\
\hline \multicolumn{9}{|l|}{ Control } \\
\hline & 16.6 & - & 0.72 & - & 75.5 & - & 4.41 & - \\
\hline \multicolumn{9}{|l|}{ Puromycin } \\
\hline $1 \times 10^{-5}$ & 6.4 & 61 & 0.43 & 40 & 54.4 & 28 & 2.29 & 47 \\
\hline $1 \times 10^{-4}$ & 3.8 & 77 & 0.44 & 39 & 51.3 & 32 & 1.87 & 57 \\
\hline $5 \times 10^{-4}$ & 1.2 & 93 & 0.22 & 69 & 12.0 & 84 & 0.97 & 77 \\
\hline \multicolumn{9}{|c|}{ DL- $p$-Fluorophenylalanine } \\
\hline $1 \times 10^{-5}$ & 10.2 & 39 & 0.62 & 14 & 53.3 & 29 & 2.66 & 38 \\
\hline $5 \times 10^{-5}$ & 10.6 & 36 & 0.40 & 44 & 47.3 & 37 & 2.62 & 39 \\
\hline $5 \times 10^{-4}$ & 8.3 & 50 & 0.44 & 39 & 32.5 & 57 & 1.96 & 55 \\
\hline \multicolumn{9}{|c|}{ 2,4-Dinitrophenol } \\
\hline $5 \times 10^{-5}$ & 6.7 & 60 & 0.56 & 22 & 39.5 & 48 & 2.86 & 34 \\
\hline $1 \times 10^{-4}$ & 5.4 & 67 & 0.44 & 39 & 21.3 & 72 & 1.87 & 57 \\
\hline \multicolumn{9}{|l|}{ Antimycin A } \\
\hline $2.5 \times 10^{-7}$ & 16.3 & 2 & 0.73 & 0 & 46.8 & 38 & 2.59 & 40 \\
\hline $2.5 \times 10^{-6}$ & 11.9 & 28 & 0.49 & 32 & 37.9 & 50 & 2.45 & 43 \\
\hline $1.25 \times 10^{-5}$ & 11.8 & 29 & 0.55 & 34 & 32.2 & 57 & 2.21 & 49 \\
\hline
\end{tabular}

* Activity of phenylalanine ammonia-lyase in the fresh tissues is 1.1 unit per disc. Polyphenol content in the fresh tissues is $0.39 \mu$ mole per disc.

** Corrected for the enzyme activity (or polyphenol content) in the fresh tissues.

Acknowledgments. The authors wish to ex- Agricultural Science, Tokyo, for supply of press their gratitude to Dr. H. D. Brown, blasticidin S. Thanks are also due to Dr. T. Merck Sharp \& Dohme Reseach Laboratories, Akazawa for his cordial help in preparation Rahway, N.J. for supply of actinomycin D, of the manuscript. and to Dr. A. Misato, National Institute of 